\title{
Nursing Care of a Patient Diagnosed with COVID-19: A Case Report According to Meleis's Transition Theory
}

\author{
Yasemin Özyer ${ }^{1}$, Safiye Yanmış² \\ ${ }^{1}$ Erzincan Binali Y1ldırım University, Faculty of Health Science, Department of Internal Medicine Nursing, Erzincan, Turkey.
}

Received: 12 June 2020, Accepted: 02 November 2020, Published online: 31 December 2020

(C) Ordu University Institute of Health Sciences, Turkey, 2020

\begin{abstract}
The transition theory developed by Afaf İbrahim Meleis is a nursing theory aimed at defining changes in individuals' lives and improving their health. Effects of such changes and transitions on individuals' health differ from one person to another. Nurses assist patients in these transition times by developing different intervention methods for them. Meleis' s transition theory is of importance because it is based on nursing profession and has contributed to the emergence of nursing science. A female patient presented to a private health institution with complaints of fever $\left(38.2^{\circ} \mathrm{C}\right)$ and sore throat. The result of the 2019-nCov test performed was positive and she was quarantined in a socially isolated room of the hospital. Uncertainty and fear of death due to COVID-19, a global epidemic, bring about serious consequences for patients. In this case report, in line with Meleis' $\mathrm{s}$ transition theory, nursing care was planned for this 52-year-old woman diagnosed with 2019-nCov.
\end{abstract}

Key words: Coronavirus, 2019-nCov, pandemic, Meleis's transition theory, Nursing care.

Suggested Citation: Ozyer Y, Yanmis S. Nursing Care of a Patient Diagnosed with COVID-19: A Case Report According to Meleis' s Transition Theory. Middle Black Sea Journal of Health Science, 2020; 6(3):412-416.

Address for correspondence/reprints:

Safiye Yanmış

Telephone number: +90 (543) 3496155

ORCID-ID 0000-0002-9095-4048

E-mail: safiyeyanmis61@gmail.com

DOI: $10.19127 / \mathrm{mbsjohs.751960}$

\section{Introduction}

On the last day of December 2019, cases of pneumonia of unknown cause, believed to have emerged from a seafood market in Wuhan City, Hubei Province of China, were reported to the World Health Organization (WHO) (Lu et al., 2020). The investigation conducted in the region revealed that this situation was caused by the Wuhan corona virus. The clinical symptoms of the disease were fever and dyspnea, and bilateral pulmonary inflammation in the chest x-ray. The WHO named this disease '2019nCov' and declared the case a "pandemic." As the virus spread rapidly around the world, countries took precautions accompanied by social restrictions implemented at various levels against the pandemic (Dunlop et al., 2020; EU, 2020). In our country, Turkey, since March 10, 2020, the cases of 2019- 
nCov have started to appear (TUBITAK, 2020). This disease, which has been affecting the whole world since December 2019, causes uncertainty, fear and panic in individuals. In addition, the transition from a healthy life to an uncertainty and disease causes fear of death in individuals (WHO, 2020).

Changes in health and illness of individuals create a process of transition, and clients in transition tend to be more vulnerable to risks that may in turn affect their health. Uncovering these risks may be enhanced by understanding Meleis' $\mathrm{s}$ transition process. The concept of transition, as described in nursing, is complex and multidimensionally identified as awareness, engagement, change and difference, time span, critical points and events (Figure 1) (Meleis et al., 2000).

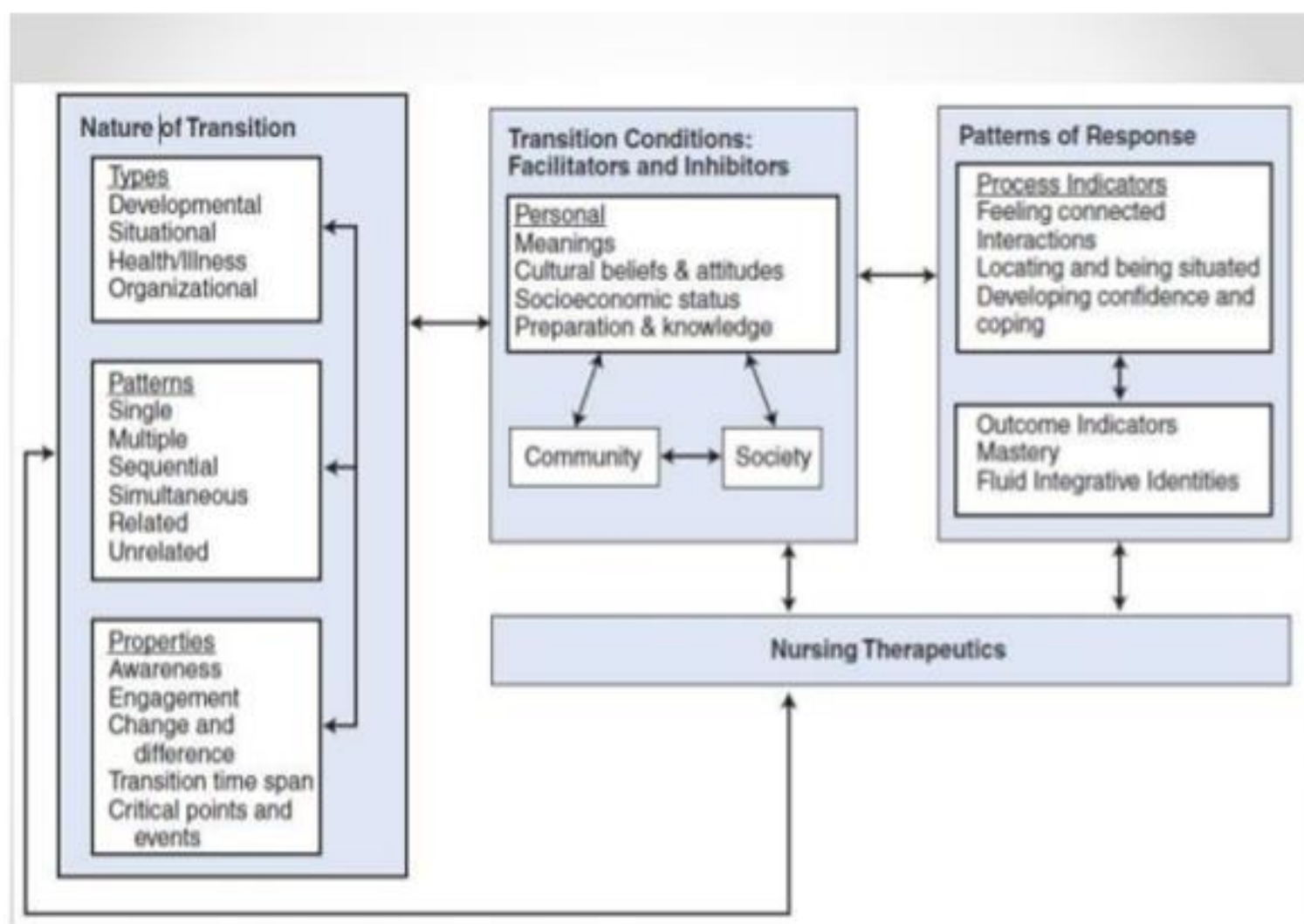

Figure 1. Middle-Range Transition Theory (Meleis AI, Sawyer LM, Im EO, Hilfinger Messias DK, Schumacher $\mathrm{K}$. Experiencing transitions: an emerging middle-range theory. Adv nurs sci 2000;23(1):12-28.)

\section{Awareness}

Awareness is related to perception, knowledge, and recognition of a transition experience. Level of awareness is often reflected in the degree of congruency between what is known about processes and responses and what constitutes an expected set of months of responses and perceptions of individuals undergoing similar transitions (Meleis et al., 2000; Davies, 2010).

\section{Engagement}

Another property of transitions is the level of engagement in the process. Engagement is defined as the degree to which a person demonstrates involvement in the processes inherent in the transition. Examples of engagement are seeking out information, using role models, actively preparing, and proactively modifying activities (Meleis et al., 2000; Davies, 2010).

\section{Changes and differences}

Changes and differences are a property of transitions. Changes in identities, roles, relationships, abilities, and patterns of behavior are supposed to bring a sense of movement or direction to internal processes, as well as external processes (Meleis et al., 2000; Davies, 2010). Meleis et al. (2000) asserted that all transitions involve change, whereas not all change is related to transition. Then, they suggested that to fully understand a transition 
process, it is necessary to uncover and describe the effects and meanings of the changes involved and the dimensions of changes (e.g., nature, temporality, perceived importance or severity, personal, familial, and societal norms and expectations). Differences are also suggested as a property of transitions. Meleis et al. (2000) believed that confronting differences could be exemplified by unmet or divergent expectations, feeling different, being perceived as different, or seeing the world and others in different ways, and suggested that it might be useful for nurses to consider a client's level of comfort and mastery in dealing with changes and differences.

\section{Time Span}

Time span is also a property of transitions and all transitions may be characterized as flowing and moving over time (Meleis et al., 2000; Davies, 2010). According to the assertion by Bridges (1991) in the middle range theory of transition, transition is defined as a span of time with an identifiable starting point, extending from the first signs of anticipation, perception, or demonstration of change; moving through a period of instability, confusion, and distress; to an eventual "ending" with a new beginning or period of stability. However, Meleis et al. (2000) also made the point that it might be difficult or impossible, and perhaps even counterproductive, to put boundaries on the time span of certain transition experiences.

\section{Critical Points and Events}

Some transitions are associated with an identifiable marker event; such as birth, death, the cessation of menstruation, or the diagnosis of an illness; whereas in other transitions, specific marker events are not as evident. The various studies involving multiple transitions provided evidence that most transition experiences involved critical turning points or events. In addition, there is final critical points, which were characterized by a sense of stabilization in new routines, skills, lifestyles, and selfcare activities. Each milestone requires the nurse's attention, knowledge and experience in different ways (Meleis et al., 2000; Davies, 2010).

In this case report, based on Meleis' $\mathrm{s}$ transition theory, nursing care was planned for a 52-year-old woman diagnosed with 2019-nCov. Our review of the literature demonstrated that no study in which nursing care was planned in line with Meleis' s transition theory for patients diagnosed with 2019nCov was conducted. Thus, we expect that our case report would significantly contribute to the current literature.

\section{Case}

The study was carried out in line with the principles of the Helsinki Declaration. Approval was received for this study from the patient. The patient MA is a 52-year-old woman and married. She presented to a private health institution on April 1, 2020 with complaints of fever $\left(38.2^{\circ} \mathrm{C}\right)$ and sore throat. The results of the routine biochemistry and hemogram tests indicated the following: AST $=88$ $\mathrm{UL}(0-50 \mathrm{UL}), \mathrm{ALT}=75 \mathrm{UL}(0-50 \mathrm{UL}), \mathrm{CRP}=120$ $\mathrm{mg} / \mathrm{L}(0-5 \mathrm{mg} / \mathrm{L}), \mathrm{IG} \%=3.7(0-0), \mathrm{HCT}=36.4 \%$ (40-53\%), RDW-S = 37.5 (0-0), P-LCR = $21(0-0)$. The patient, who was diagnosed with tuberculosis (TBC) at the age of 17, underwent chest X-ray and computed tomography (CT) for the diagnosis. The diagnostic methods revealed no pathological findings. In the oropharyngeal swab sample of the patient, the result of the diagnosis test of 2019nCovwas positive. Therefore, the anamnesis of the patient was obtained, which demonstrated that 2019nCov was transmitted to her from her husband who shared the same house with her. In line with this result, the patient was quarantined in a hospital room where isolation measures were taken. The patient was intravenously administered moxifloxacin (3x400mg) and esomeprazole $(2 \times 40 \mathrm{mg})$. The patient suffered intensive feelings of anxiety, hopelessness, obscurity and fear due to the diagnosis and treatment procedures and isolation measures she underwent. Therefore, nursing care was planned for her based on Meleis's transition theory.

-In this period, the awareness phase of the transition theory, the patient was informed

about her illness, and treatment and isolation measure she was to undergo. Her fears and worries were resolved so that she could express herself. Her physiological and psychological needs were determined.

-At the stage of taking responsibility, she was encouraged to take part in her own physical

and spiritual care, which supported her to be aware of self-care.

-In the stage of change and differences, the patient, who was under quarantine and tried

to adapt to the difficult process, was enabled to cope with and adapt to this situation.

-At the time process stage, she was told the process of transition from disease to health

is like the transition period from health to disease and was given mental support that this situation would bring about new beginnings. 
-In the stage of critical points and events, she was given information about new routines, lifestyles, and selfcare activities.

It is important for a nurse to provide nursing care to the patient by using his or her knowledge and skills during events such as illness, a turning point in a person's life. At this stage, nursing interventions to meet the patient's needs were planned. Her physical, psychological and spiritual needs were met by providing holistic, supportive and individual care to her.

\section{Discussion}

The number of people infected with 2019-nCov is increasing dramatically worldwide. The disease has led to a chain of infections representing the largest outbreak outside Asia to date (Spina et al., 2020). In Turkey, the first transmission from person to person was reported on March 10, 2020. As of April 14, 2020, In Turkey, the numbers of positive cases, deaths and survivors were reported as 65,111 , 1,403 and 4,799 respectively ranging from hour to hour (TUBITAK, 2020). This outbreak of the disease causes uncertainty, fear and panic in individuals and the society due to the day-by-day increase in its severity (WHO, 2020). Nurses play a great role in the transition both from health to illness and from illness to health in this pandemic, since they are healthcare workers who care for both healthy and sick individuals in different situations such as health, illness, birth and death (Bekmezci et al., 2016; Lindmark et al., 2019). The transition theory developed by Afaf İbrahim Meleis is involved in the meaning that an individual attribute to the transition, and his or her expectations about the transition, knowledge and skill levels, and emotional and physical well-being ( Davies, 2010; Bekmezci et al., 2016; Aydin and Kukulu, 2020). In case that the patient suffers from such feelings as fear of death and hopelessness when his or her diagnosis of COVID19 is positive, nurses' answering the patient's questions, alleviating his or her fears and informing him or her about the disease are among the factors that facilitate the transition period. In our case, supportive care and education given to the patient increased her satisfaction, contributed to the improvement of her symptoms and her self-care, and improved her health and well-being. In this pandemic, maintaining the physical care of a patient and reducing his or her complications are among the responsibilities of the nurse. The patient who was provided nursing care in accordance with Meleis's transition theory was discharged from the hospital on April 15, 2020 by taking the necessary protective measures after her symptoms and test results improved thanks to the treatment and care given to her, and the result of her COVID-19 diagnostic test was negative.

\section{Conclusion}

Nurses' putting theories into practice and disseminating and supporting them in the care process of COVID-19 epidemic disease are of great importance. In this transition from disease to health stage of this pandemic, using Meleis' s transition theory in nursing care will increase the effect and quality of the physical, psychological and spiritual care, and will provide a holistic support to the patient. This theory is a useful model for nurses to plan and implement nursing care for patients who are in the transition period.

Ethics Committee Approval: Approval was received for this study from the patient.

Peer-review: Externally peer-reviewed.

Author Contributions: Concept- Y.O, S.Y; Design- Y.O, S.Y; Materials- Y.O, S.Y; Data Collection and/or Processing- Y.O, S.Y; Literature Review- Y.O, S.Y; Writing- Y.O, S.Y; Critical Review- Y.O, S.Y.

Conflict of Interest: No conflict of interest was declared by the authors.

Financial Disclosure: The authors declared that this study hasn't received no financial support.

\section{References}

Aydin R, Kukulu K. The importance and process of using theory in nursing researches. J Hum Sci 2020;17(1):389-403.

Bekmezci H, Hamlaci Y, Ozerdogan N. Postpartum Care Based on The Meleis' Transition Theory. Gumushane Univ J Heal Sci 2016;5(4):101-6.

Bridges W. Managing transitions: Making the most of change. Menlo Park, CA: Addison Wesley; 1991. p. 78-96.

Davies S. Meleis' s Theory of Nursing Transitions And Relatives' Experiences of Nursing Home Entry. In: Meleis AI, editor. Transitions Theory: Middle Range and Situation Spesific Theories in Nursing Research And Practices. New York: Springer Publishing Company; 2010. p. 212. 
Dunlop C, Howe A, Li D, Allen LN. The coronavirus outbreak: the central role of primary care in emergency preparedness and response. BJGP Open 2020;4(1): bjgpopen20X101041. doi: 10.3399/bjgpopen20X101041

European Commission (EU). Coronavirus crisis: Commission will use all the tools at its disposal to make sure the European economy weathers the storm. [cited 2020 Apr 14]. Available from: https://ec.europa.eu/commission/presscorner/det ail/en/ip_20_440

Meleis AI, Sawyer LM, Im EO, Hilfinger Messias DK, Schumacher K. Experiencing transitions: an emerging middle-range theory. Adv nurs sci 2000;23(1):12-28.

Lindmark U, Bülow PH, Mårtensson J, Rönning H, Group ADULTR. The use of the concept of transition in different disciplines within health and social welfare: An integrative literature review. Nursing Open 2019;6(3):664-75. doi: https://doi.org/10.1002/nop2.249

Lu H, Stratton CW, Tang Y-W. Outbreak of pneumonia of unknown etiology in Wuhan, China: The mystery and the miracle. J Med Virol 2020;92(4):401-2. doi: 10.1002/jmv.25678

Spina S, Marrazzo F, Migliari M, Stucchi R, Sforza A, Fumagalli R. The response of Milan's Emergency Medical System to the COVID-19 outbreak in Italy. The Lancet 2020;395(10227):e49-50. doi: https://doi.org/10.1016/S0140-6736(20)30493-1

TUBITAK. Situation in Turkey. [cited 2020 Apr 14]. Available from: https://covid19.tubitak.gov.tr/turkiyede-durum

World Health Organisation (WHO). Mental health and psychological resilience during the COVID19 pandemic. [cited 2020 Apr 14]. Available from: http://www.euro.who.int/en/healthtopics/health-emergencies/coronavirus-covid19/news/news/2020/3/mental-health-andpsychological-resilience-during-the-covid-19pandemic 